\title{
O trabalho das equipes multiprofissionais na educação:10 anos do grupo de pesquisa TEDis
}

\section{The work of multiprofessional teams in education: 10 years of the TEDis research group}

\author{
Andréa Márcia Legnani ${ }^{1}$
}

\begin{abstract}
RESUMO: O livro " $O$ trabalho das equipes multiprofissionais na educação: 10 anos do grupo de pesquisa TEDis" foi organizado por Sílvia Cristina Yannoulas e escrito com a colaboração de diversos pesquisadores envolvidos com as temáticas educacionais e de serviço social. Essa obra, objeto desta resenha, é composta de duas partes com seis capítulos, sendo que na primeira parte do livro apresenta relevantes experiências sobre o trabalho de equipes multiprofissionais, desenvolvido em instituições de ensino superior pela via do Plano Nacional de Assistência Estudantil (PNAES), instituído pelo Decreto N. 7.234, de 19 de julho de 2010. A segunda parte traz a reflexão sobre a inserção de equipes multiprofissionais nas escolas de Educação Básica, procurando repassar para o leitor que é necessário compreender que um trabalho multiprofissional deve estar direcionado para a garantia de direitos sociais e execução de políticas sociais e educacionais por meio da dinâmica da intersetorialidade.
\end{abstract}

PALAVRAS-CHAVE: Educação; Equipes multiprofissionais.

\begin{abstract}
The book "O trabalho das equipes multiprofissionais na educação: 10 anos do grupo de pesquisa TEDis" was organized by Sílvia Cristina Yannoulas and was written with the collaboration of several researchers involved with educational and social work topics. This work, the object of this review, is composed of two parts with six chapters, and in the first part of the book relevant experiences are presented on the multiprofessional teams' work, developed in higher education institutions by the means of the National Student Assistance Plan (PNAES), instituted by Decree n.7.234 of July 19, 2010. The second part reflects on the multiprofessional team's presence in Basic Education schools, attempting to convey to the reader that it is necessary to understand that a multiprofessional work should be directed to guarantee social rights and to implement social and educational policies through the dynamics of intersectoriality.
\end{abstract}

KEYWORDS: Education; Multiprofessional teams.

\section{INTRODUÇÃO}

A obra intitulada "O trabalho das equipes multiprofissionais na educação 10 anos de grupo de pesquisa TEDis”, foi organizada por Sílvia Cristina Yannoulas, professora do Departamento de Serviço Social da Universidade de Brasília (UnB), onde atua no Programa de Pós-Graduação em

1 Pedagoga do Instituto Federal do Paraná Campus Foz do Iguaçu, Doutoranda do Programa de Pós-Graduação, Stricto Sensu, em Sociedade, Cultura e Fronteiras da Universidade Estadual do Oeste do Paraná. ORCID ID: 0000-0001-63861631. E-mail: andrea.legnani@hotmail.com 
Política Social (PPGPS), desde 2006; lidera o Grupo de Pesquisa "Trabalho, Educação e Discriminação" (TEDis), desde 2007.

O livro publicado em 2017 pela Editora CRV, sediada em Curitiba-Paraná, com 242 páginas, foi escrito com a colaboração de diversos pesquisadores envolvidos com as temáticas educacionais e de serviço social e possibilita aos leitores a oportunidade de conhecer, refletir e compreender a respeito do cotidiano do trabalho de equipes multiprofissionais na área da educação.

Apesar de ser uma obra publicada em 2017, traz abordagens atuais e relevantes sobre a temática das equipes multiprofissionais em contexto educacional principalmente porque recentemente foi legislada em nível federal, a Lei N. 13.935, de 12 dezembro de 2019, que dispõe sobre a prestação de serviços de psicologia e de serviço social nas redes públicas de educação básica.

\section{DESENVOLVIMENTO}

A obra inicia com um prefácio escrito pela professora Maria Helena Elpidio Abreu que, à época, era presidente da Associação Brasileira de Ensino e Pesquisa em Serviço Social (Abepss). O livro está dividido em duas partes com seis capítulos e um posfácio.

A primeira parte do livro, que contempla três capítulos, apresenta relevantes experiências sobre o trabalho de equipes multiprofissionais, desenvolvido em instituições de ensino superior pela via do Plano Nacional de Assistência Estudantil (PNAES), instituído pelo Decreto N. 7.234, de 19 de julho de 2010.

No primeiro capítulo, os autores Carolina Cassia Batista Santos, Patrícia Paulino Muniz de Abrantes e Rafael Zonta, apresentam um trabalho de aproximação entre o conhecimento teórico científico, das vivências da prática profissional e a experiência de reorganização dos processos de trabalho da equipe multiprofissional da assistência estudantil no Decanato de Assuntos Comunitários da Universidade de Brasília (DAC/UnB). Também fazem uma discussão sobre a educação superior no Brasil, abordando aspectos históricos e os processos que levaram a políticas de democratização do acesso e inclusão social no ensino superior brasileiro. Em seguida, tratam da temática da assistência estudantil como direito de permanência na educação superior, levando em consideração políticas implantadas, conceitos e contextos. Depois pontuam sobre trabalho de equipes multiprofissionais, considerando o campo específico da assistência estudantil. Para finalizar, desenvolvem a análise da experiência sobre o trabalho da equipe multiprofissional da assistência estudantil na UnB. Os escritores concluem que, apesar do PNAES possibilitar avanços, as políticas nacionais voltadas para assistência estudantil ainda são insuficientes, pois são estabelecidas por programas governamentais com orçamento reduzido diante da crescente demanda. 
Ainda fazem uma reflexão no contexto da equipe multiprofissional da UnB, como um espaço para o exercício da intersetorialidade na relação de seus saberes específicos em torno de um objetivo comum, destacando o esforço da equipe técnica em contribuir para o aumento das ações de qualidade nos atendimentos, de acompanhamentos aos beneficiários, encaminhamentos às redes intersetoriais de assistência social e principalmente no controle e transparência das ações e dos gastos públicos com a política de assistência estudantil.

No segundo capítulo, elaborado pelas autoras Potyara Amazoneida P. Pereira e Jacqueline Domiense Almeida de Souza, é apresentado o debate teórico sobre a questão da assistência estudantil como direito ou mérito. Para tanto, partem da problematização do conceito do substantivo "assistência" no que se refere ao estudante, fazendo uma correlação entre as políticas de assistência estudantil e de educação. Destacam ainda que a assistência ao estudante vem ocupando uma posição secundária no ambiente educacional, ou mesmo dispensável e que, além disso, observa-se nesse ambiente o distanciamento do vínculo entre Assistência Estudantil e a Política de Assistência Social. Por isso, na contramão da visão hegemônica, de uma parcela dos integrantes do ambiente educacional que tem uma perspectiva de que a Assistência Estudantil pode tornar-se "assistencialismo", as autoras consideram a Assistência Estudantil uma ramificação da Política Pública de Assistência Social que, devido a sua característica intersetorial, desenvolve-se no interior da Educação como coadjuvante do processo de universalização desta. As autoras destacam que pensar a Assistência Estudantil como uma unidade complexa que resulta, dentre outras participações, do vínculo orgânico entre Assistência Social e Educação, é guiar-se por uma perspectiva universalizante da educação como política pública e direito de cidadania. Observam ainda que, é possível vislumbrar uma articulação colaborativa entre as políticas públicas de Assistência e as de Educação que apesar de possuírem perfis e legitimidades sociais diferentes, partilham um mesmo objetivo: garantir aos estudantes de Universidades e Institutos Federais em vulnerabilidade socioeconômica o acesso, a permanência e a conclusão de seus estudos em condições de formação e qualificação acadêmicas iguais para todos. Apresentam ainda os marcos legais da assistência estudantil, com destaque para o PNAES, pontuando que este tem limitações no que diz respeito à garantia do direito ao acesso, permanência e conclusão dos cursos em um país com desigualdades sociais profundas como o Brasil. As escritoras concluem nesta análise da Assistência Estudantil no Brasil que uma visão separatista na Assistência Estudantil revela a sua fragilidade conceitual, pois, via de regra, recai sobre a política de Assistência Social a culpa ou o ônus dos desacertos da Assistência Estudantil e o bônus fica para a Educação. Portanto, o vínculo entre Assistência Social e Educação, mediada pela Assistência Estudantil, tem acontecido de maneira deficitária, o que tem prevalecido é a identificação da Assistência Estudantil com a 
distribuição de auxílios financeiros, sem realizar mediações com outras funções que lhe são particulares, reduzindo-a, de forma pejorativa, ao assistencialismo. Dessa forma, as autoras defendem não uma simples articulação, mas um vínculo orgânico entre a Assistência Social e a Educação, pois entendem que viabilizar acesso a benefícios e serviços assistenciais, está no centro de um propósito maior, que é universalizar a educação como política social, e não como mercadoria.

No terceiro capítulo, de autoria de Miriam de S. L. Albuquerque, Jacqueline Domiense Almeida de Souza, Laís Vieira Pinelli e Samuel Gabriel Assis, são apresentados os resultados de uma investigação sobre as equipes multiprofissionais em ambientes educacionais do ensino superior e sobre a política de educação, procurando analisar o funcionamento, os desafios e as limitações na implementação de políticas intersetoriais do trabalho multiprofissional na educação superior, no âmbito da assistência estudantil do Instituto Federal de Brasília (IFB) e sua articulação com a prática de estágio obrigatório em serviço social. As autoras organizaram o texto conforme segue: primeiramente apresentaram um breve histórico da trajetória da assistência estudantil no IFB; na sequência com base nos dados levantados, analisaram a dinâmica das equipes; e para finalizar realizaram uma exposição sobre as características, as potencialidades e desafios da inserção dos estagiários em Serviço Social nas equipes multiprofissionais. Tal estudo possibilita aos leitores reflexões e debates a respeito dos limites e potencialidades de trabalho em equipes, contribuindo assim na qualificação da formação profissional na política de assistência estudantil, pois traz uma experiência in loco que preza por uma formação acadêmica em Serviço Social capaz de fortalecer uma perspectiva de trabalho interdisciplinar como mecanismo de concretização de direitos.

A segunda parte do livro está focada na reflexão sobre inserção de equipes multiprofissionais nas escolas de Educação Básica, procurando repassar para o leitor que é necessário compreender que um trabalho multiprofissional deve estar direcionado para a garantia de direitos sociais e execução de políticas sociais e educacionais por meio da dinâmica da intersetorialidade.

No quarto capítulo, elaborado pelas autoras Sílvia Cristina Yannoulas, Mônica Girolami e Zulma Viviana Lenarduzzi, se discute o trabalho de equipes multiprofissionais em ambientes escolares formais no contexto das tendências da política educacional latino-americana contemporânea, perpassando pelo viés da Política Educacional e da Política Social, por meio de um estudo comparado entre Argentina e Brasil. O período analisado pelas autoras está delimitado entre 1930, com o surgimento da figura das Assistentes Sociais em ambos os países, e 2015, momento em que ocorreram grandes transformações nas tendências políticas nos dois países estudados. Iniciam fazendo um aporte histórico sobre a relação entre o serviço social e a educação, tanto no Brasil como na Argentina. Com o estudo em questão, as pesquisadoras observaram que em ambos países 
houve uma sequência de etapas mais ou menos definidas na relação estabelecida entre a educação obrigatória e a institucionalização de serviços e políticas sociais no sistema educacional: etapa higienista, desenvolvimentista, autoritária, democratizadora / neoliberal e democratizadora / populista. As autoras destacam a importância de compreender o vínculo entre educação e política social, frisando como primordial a intersetorialidade. Por meio dos dados levantados sobre a educação escolar, tanto do Brasil quanto da Argentina, as autoras apresentam e analisam o funcionamento, as limitações e o trabalho implementado no ensino básico obrigatório de profissionais das áreas de Serviço Social e Psicologia. Também alertam para a falta de clareza sobre as atribuições das equipes multiprofissionais na escola e uma demanda voltada às equipes para que resolvam ou atuem sobre as consequências da implementação de modelos econômicos excludentes e sobre as representações da questão social no dia a dia educacional. Para finalizar o capitulo, observam que no período pesquisado (1930-2015), há indicações de que existem pontos semelhantes e distintos sobre a inclusão do Serviço Social na Argentina e no Brasil, que partem da figura da visitadora social no modelo higienista, desenvolvendo um trabalho individual, que é realizado mais externamente, do que dentro da escola, para chegar à proposição de trabalho em equipes multiprofissionais, ao invés do desenvolvimento de um Serviço Social escolar, com equipes focadas num trabalho conjunto de vários profissionais na escola e com o objetivo de garantir o direito à educação de qualidade de todos os alunos que tem trajetórias específicas diversas. Também observam que a inclusão de equipes multiprofissionais como política de Estado no Brasil é predominante, enquanto que na Argentina é necessário o aprofundamento do papel de tais equipes e a elaboração de estratégias que possam abarcar a complexa realidade do objeto de trabalho que deve ser abordado nas escolas, bem como consolidar a sua presença no nível médio e ampliar para outros níveis do sistema de ensino. Assim, entendem que as equipes multiprofissionais seriam uma necessidade do trabalho escolar na atualidade, mas também que o debate sobre a universalização do ensino básico deveria incluir a problematização sobre o papel que os sistemas educacionais assumem na construção das políticas sociais especificas.

No quinto capítulo, desenvolvido pelas autoras Sílvia Cristina Yannoulas, Silvana Aparecida Souza, Steli Larissa Lima Ferreira Rios e Kelma Jacqueline Soares, são analisados os entraves no Congresso Nacional Brasileiro para a aprovação de legislação específica sobre a inserção de profissionais do Serviço Social e Psicologia em escolas públicas de Educação Básica, que se

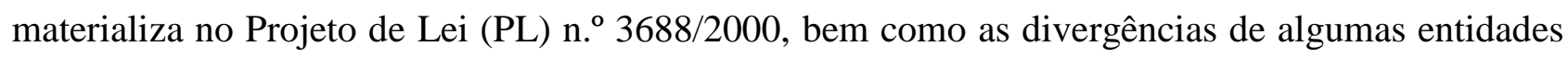
estratégicas com o referido PL, procurando destacar o potencial de contribuição crítica das equipes multiprofissionais à qualidade do processo pedagógico. O texto está organizado da seguinte maneira: primeiramente explica os percursos do debate sobre os projetos de lei no Congresso 
Nacional, suas particularidades e vicissitudes. Na sequência, apresenta os principais resultados do diálogo estabelecido pela equipe de pesquisadoras com profissionais de entidades representativas direta ou indiretamente envolvidas no debate. Finalmente, pondera sobre as hipóteses iniciais sob o prisma dos dados coletados e analisados. As autoras consideram como hipóteses desse estudo, quais sejam, o fato de que: há uma invisibilidade das equipes multiprofissionais já envolvidas no trabalho escolar no Brasil, o que gera certo desconhecimento da relevância e natureza do trabalho que elas possam desenvolver; pode haver razões econômicas na origem das divergências das entidades signatárias da Carta Aberta de iniciativa da União Nacional dos Dirigentes Municipais de Educação (Undime). Também compreendem que, além da necessidade de formação especifica de atuação das assistentes sociais em política educacional e de pedagogas em questão social e de proteção integral à criança e ao adolescente, é preciso um investimento em pesquisa e formação para trabalho em equipes multiprofissionais para facilitar o diálogo e a construção coletiva de alternativas para melhorar a qualidade da Educação Básica. Outro fator destacado como importante é dar visibilidade ao trabalho das equipes multiprofissionais já existentes, tanto no Brasil, quanto em outros países, sobretudo da América Latina - por compartilhar manifestações semelhantes da questão social.

No sexto capítulo, elaborado pela autora Eliana Bolorino Canteiro Martins, são apresentadas algumas informações referentes à definição e função dos grupos de pesquisa para chegar à explanação sobre o processo de implantação do GEPESSE (Grupo de Estudos e Pesquisas sobre Serviço Social na Educação), descrevendo e interpretando a trajetória histórica das edições do "Fórum do Serviço Social na Educação", oportunizando reflexões sobre a sua relevância e as contribuições para os profissionais do Serviço Social, especialmente àqueles que trabalham na Política de Educação no Brasil.

Para encerrar o livro de maneira a destacar a importância da atuação de outros grupos de pesquisa bem como do próprio TEDis, as pesquisadoras Silvia Cristina Yannoulas, Carolina Cassia Batista Santos e Natália de Souza Duarte discorrem sobre trajetória de dez anos de atuação do grupo, que desde de 2007 vem promovendo estudos sobre a categoria "Trabalho", articulado ao conhecimento e à educação formal, considerando as questões de classe social, gênero e raça/etnia, utilizando uma abordagem intersetorial e multiprofissional.

\section{CONSIDERAÇÕES FINAIS}

Em termos gerais, pode-se dizer que a ênfase do livro está em salientar que, apesar dos desafios e dificuldades referentes ao trabalho das equipes multiprofissionais relatadas na obra, pode-se considerar que as contribuições dessas experiências apresentam aspectos positivos e que é, portanto, primordial ampliar o diálogo entre as áreas disciplinares na construção de novos saberes e 
novas práticas, assim como introduzir e consolidar o trabalho multiprofissional no ambiente educacional.

Diante do que foi exposto, recomenda-se a leitura da obra resenhada, considerando-se que uma reflexão aprofundada a respeito do trabalho de equipes multiprofissionais no âmbito escolar faz-se necessária pela importância da aproximação das áreas do Serviço Social, da Psicologia e da Educação com vistas à melhoria da qualidade da educação e da necessidade de pedagogos e demais educadores conhecerem mais sobre os vínculos e articulações possíveis com tais áreas para o desenvolvimento do trabalho conjunto de tais profissionais no espaço educacional.

\section{REFERÊNCIA}

YANNOULAS, S. C. (Coord.). O trabalho das equipes multiprofissionais na Educação: 10 anos do grupo de pesquisa TEDis. Curitiba [PR]: CRV, 2017. 242p. Disponível em: http://www.tedis. unb.br/capitulos-e-livros/266-o-trabalho-das-equipes-multiprofissinais-na-educacao-10-anos-do-gru po-de-pesquisa-tedis. Acesso em: 4 fev. 2020. 